\title{
Antinociceptive Properties of Bergenin
}

Cristiane Metzker de Oliveira, ${ }^{\dagger}$ Fabiana Regina Nonato, ${ }^{\ddagger}$ Flávia Oliveira de Lima, ${ }^{\S}$ Ricardo David Couto, ${ }^{\dagger}$ Juceni P. David, ${ }^{\dagger}$ Jorge M. David, ${ }^{\dagger}$ Milena Botelho Pereira Soares, ${ }^{\neq, \perp}$ and Cristiane Flora Villarreal ${ }^{*,+, \neq}$

${ }^{\dagger}$ Universidade Federal da Bahia, Salvador, BA, Brazil

${ }^{\ddagger}$ Centro de Pesquisas Gonçalo Moniz, Fundação Oswaldo Cruz, Salvador, BA, Brazil

${ }^{\S}$ Universidade Estadual de Feira de Santana, Feira de Santana, BA, Brazil

${ }^{\perp}$ Centro de Biotecnologia e Terapia Celular, Hospital São Rafael, Salvador, BA, Brazil

Supporting Information

ABSTRACT: Bergenin (1) is a C-glucoside of 4-O-methylgallic acid with known antiarthritic activity attributed to modulation of cytokine production. The present study was undertaken to evaluate whether 1 has antinociceptive properties in models of inflammatory pain and to investigate its possible mechanisms of action. Pretreatment with $1(12.5-100 \mathrm{mg} / \mathrm{kg}$, ip) produced a dose-related inhibition of acetic acid-induced writhing in mice. Furthermore, treatment with 1 (50 and $100 \mathrm{mg} / \mathrm{kg}$ ) inhibited both the early and late phases in a formalin test. In addition, 1 (50 and $100 \mathrm{mg} / \mathrm{kg}$, ip) inhibited mechanical hyperalgesia, edema, and paw production of hyperalgesic cytokines (TNF- $\alpha$ and IL-1 $\beta$ ) induced by complete Freund's adjuvant. However, the local production of IL-10, an anti-inflammatory

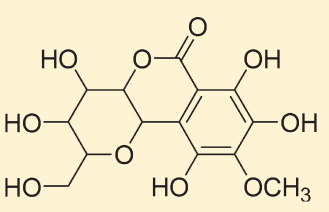

1 cytokine, was not altered by $\mathbf{1}(100 \mathrm{mg} / \mathrm{kg}$, ip). Treatment with $\mathbf{1}$ produced a similar profile of antinociception in wild-type and IL10-deficient mice. Mice treated with 1 did not show any motor performance alterations or apparent systemic toxicity. The results presented herein demonstrate that bergenin has consistent antinociceptive and anti-inflammatory properties, acting by the inhibition of IL-1 $\beta$ and TNF- $\alpha$ production, and suggest its potential for the control of inflammatory pain.

$\mathrm{B}$ ergenin (1) is a $\mathrm{C}$-glucoside of 4-O-methylgallic acid that occurs naturally in several plant genera. Different studies have shown various pharmacological effects of $\mathbf{1}$, such as antiinflammatory, ${ }^{1}$ antitussive, ${ }^{2}$ hypolipidemic, ${ }^{3}$ anti-HIV, ${ }^{4}$ antiarrhythmic, ${ }^{5}$ hepatoprotective, ${ }^{6}$ neuroprotective, ${ }^{7}$ and gastroprotective activities. ${ }^{8}$ In addition, Nazir et al. ${ }^{9}$ demonstrated that $\mathbf{1}$ exhibits a potent antiarthritic activity by modulating Th1/Th2 cytokine production.

It is well accepted that cytokines constitute a link between cellular injuries and signs of inflammation, e.g., in cell migration, edema, fever, and hyperalgesia. ${ }^{10-12}$ In contrast with nonsteroidal anti-inflammatory drugs (NSAIDs), widely used medications to treat pain and inflammatory conditions, inhibitors of cytokine production can exhibit disease-modifying activities, thus representing an alternative therapeutic strategy for the control of inflammatory diseases.

Pain is one of the classic signs of the inflammatory process. Inflammatory pain is induced by different chemical mediators released during an inflammatory process, which cause nociceptive sensitization. The sensitization of primary nociceptive neurons is a common denominator of all kinds of inflammatory pain that lead to a state of hyperalgesia (an increased response to a stimulus that is normally painful) and allodynia (pain due to a stimulus that does not normally provoke pain). ${ }^{13}$ The balance between proand anti-inflammatory cytokine production modulates the intensity of inflammatory hyperalgesia. ${ }^{14}$ The inflammatory stimuli or tissue injuries stimulate the release of hyperalgesic cytokines that act directly on nociceptors and trigger the release of final mediators responsible for inflammatory pain. ${ }^{15}$ On the other hand, anti-inflammatory cytokines, such as interleukin (IL)-10 and IL4 , inhibit the production of hyperalgesic cytokines and final mediators, reducing hyperalgesia. ${ }^{16,17}$ Considering the key role of cytokines during inflammatory hyperalgesia and the reported modulatory activity of $\mathbf{1}$ on cytokine production, the present study was undertaken to evaluate whether $\mathbf{1}$ has antinociceptive properties and to determine its effects in modulation of cytokine production in inflammatory pain models. In addition, the systemic toxicity associated with the daily administration of $\mathbf{1}$ to mice was evaluated.<smiles>COc1c(O)c(O)c2c(c1O)C1OC(CO)C(O)C(O)C1OC2=O</smiles>

bergenin (1)

\section{RESULTS AND DISCUSSION}

The present study has demonstrated, for the first time, that systemic administration of bergenin (1), at doses that did not induce any systemic toxicity or motor performance alteration, produced consistent antinociceptive effects in different models of inflammatory pain. The antinociceptive effect due to $\mathbf{1}$ is probably a

Received: March 15, 2011

Published: September 22, 2011 


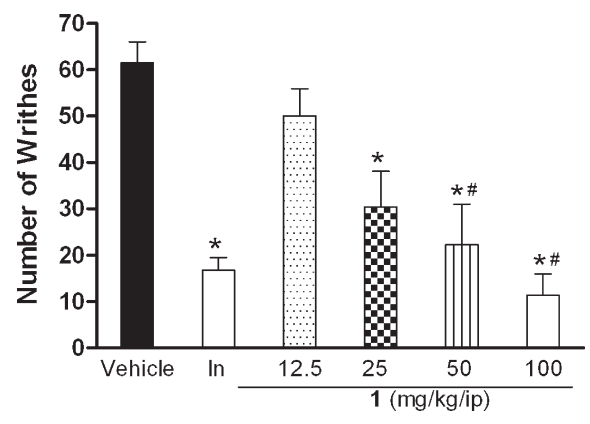

Figure 1. Effects of ip administration of bergenin (1) on acetic acidinduced writhing in mice. Mice were treated with $1(12.5-100 \mathrm{mg} / \mathrm{kg}$, ip) or vehicle ( $2 \%$ DMSO in saline; control group) by the ip route $40 \mathrm{~min}$ before acetic acid $0.8 \%$ (injected at time zero). Indomethacin (In; $10 \mathrm{mg} / \mathrm{kg}$, ip) was the positive control. Data are expressed as means \pm SEM; $n=6$ mice per group. ${ }^{*}$ Significantly different from the control group $(p<0.01)$; ${ }^{\#}$ significantly different from the $12.5 \mathrm{mg} / \mathrm{kg}$ group $(p<$ $0.05)$, as determined by ANOVA followed by Tukey's test.

result of the inhibition of IL-1 $\beta$ and TNF- $\alpha$ release, while IL-10 production is not involved.

The antinociceptive properties of 1 were evaluated initially using the writhing test in mice, a screening tool for the assessment of analgesic or anti-inflammatory properties of new substances. ${ }^{18}$ Intraperitoneal (ip) administration of $\mathbf{1}(12.5-100 \mathrm{mg} / \mathrm{kg}) 40 \mathrm{~min}$ before an acid injection produced a significant and dose-related inhibition of acetic acid-induced abdominal constrictions in mice (Figure 1). Indomethacin $(10 \mathrm{mg} / \mathrm{kg}$, ip), a standard NSAID used as positive control, also produced a significant inhibition of the acetic acid-induced writhing response. The antinociceptive effect of 1 was confirmed using a formalin test, a model of inflammatory pain with two distinctive phases that may indicate different types of pain. ${ }^{19}$ The early phase (nociceptive) is a result of direct stimulation of nociceptors and reflects centrally mediated pain; the late phase (inflammatory pain) is caused by local inflammation with a release of inflammatory and hyperalgesic mediators. ${ }^{19}$ Injection of formalin in control animals induced a biphasic flinching response, with the early phase ranging from 0 to $10 \mathrm{~min}$ (Figure 2a) and the late phase from 10 to $60 \mathrm{~min}$ (Figure $2 \mathrm{~b}$ ) after the injection. Treatment with 1 (50 and $100 \mathrm{mg} / \mathrm{kg}$, ip) or indomethacin $(10 \mathrm{mg} / \mathrm{kg}$, ip), $40 \mathrm{~min}$ before the formalin, caused antinociceptive effects in both the early and late phases of this test. Moreover, relaxing or motor deficit effects were discarded, since administration of 1 at therapeutic doses did not affect the motor performance of the mice, as tested in the Rotarod (Figure 3a) and open field (Figure 3b) tests. As expected, the central nervous system depressant diazepam $(10 \mathrm{mg} / \mathrm{kg}$, ip) reduced the time of mice on the Rotarod and the number of crossings on the open field, after $30 \mathrm{~min}$ of treatment with this standard drug. This result corroborates the antinociceptive effect of $\mathbf{1}$ as suggested by the nociceptive tests.

Considering the inhibitory property of $\mathbf{1}$ on the second phase of formalin, it may be suggested that its antinociceptive activity is due, at least in part, to an anti-inflammatory action. In line with this proposal, $\mathbf{1}$ is reported to have anti-inflammatory activity. ${ }^{1,20}$ In an attempt to verify the relationship between the antinociceptive and anti-inflammatory properties of this compound, the effects of treatment with 1 were assessed in an experimental protocol used for screening of new anti-inflammatory drugs: the complete Freund's adjuvant (CFA)-induced paw inflammation model. Mechanical hyperalgesia and paw edema were evaluated throughout the experimental period. Administration of 1 ( 50 and $100 \mathrm{mg} / \mathrm{kg}$,
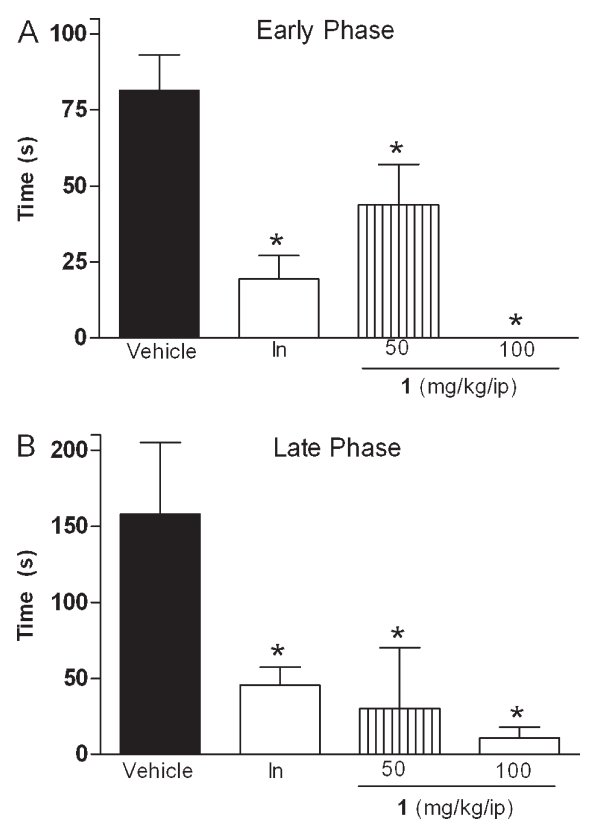

Figure 2. Effects of the bergenin (1) treatment on inflammatory pain induced by formalin. Panels (a) and (b) represent effects of $\mathbf{1}$ on the early and late phases of formalin-induced nociception in mice, respectively. Mice were treated with 1 (50 and $100 \mathrm{mg} / \mathrm{kg}$ ) or vehicle $(2 \%$ DMSO in saline; control group) by the ip route $40 \mathrm{~min}$ before formalin (injected at time zero). Indomethacin (In; $10 \mathrm{mg} / \mathrm{kg}$, ip) was the positive control. Data are expressed as means \pm SEM; $n=6$ mice per group. * Significantly different from the control group $(p<0.001)$ as determined by ANOVA followed by Tukey's test.
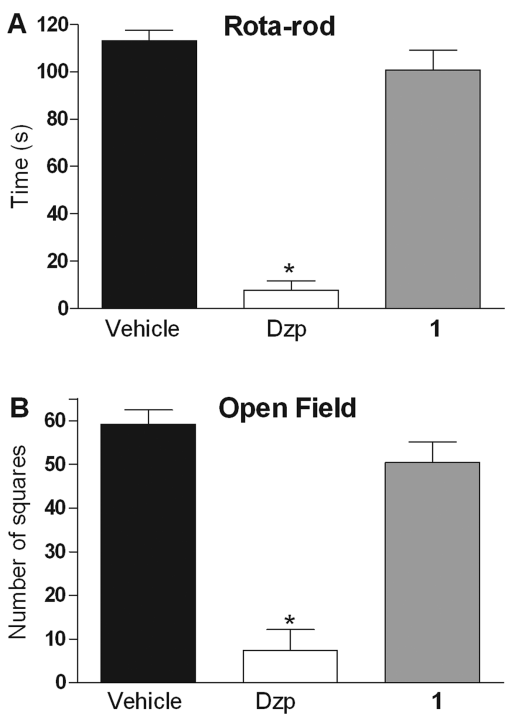

Figure 3. Effects of bergenin (1) on motor function. Bar graphs representing (a) the run time on the Rotarod and (b) the number of square crossings in the open field test, $40 \mathrm{~min}$ after the ip injection of $\mathbf{1}$ $(100 \mathrm{mg} / \mathrm{kg}$ ), diazepam (Dzp; $10 \mathrm{mg} / \mathrm{kg}$ ), or vehicle (2\% DMSO in saline; control group). Data are reported as means \pm SEM; $n=6$ mice per group. *Significantly different from the control group $(p<0.001)$. One-way ANOVA followed by Tukey's test.

ip), 40 min before CFA, reduced significantly mechanical hyperalgesia (Figure 4a) and paw edema $2 \mathrm{~h}$ (Figure $4 \mathrm{~b}$ ) and $4 \mathrm{~h}$, but not $6 \mathrm{~h}$ (Figure 4c), after the stimuli. The results obtained with 
control groups supported the effects observed for $\mathbf{1}$, since the vehicle ( $2 \%$ DMSO in saline) had no activity, whereas the positive control dexamethasone $(2 \mathrm{mg} / \mathrm{kg})$ inhibited CFA-induced hyperalgesia and edema. It is important to mention that pretreatment with 1 did not alter the baseline nociceptive threshold of the animals (not shown in Figure 4).

It has been demonstrated that natural products are sources of cytokine production inhibitors. ${ }^{21,22}$ On the basis of the proposed immunomodulatory activity of $\mathbf{1}$, it was evaluated whether or not the antinociceptive and anti-inflammatory effects of $\mathbf{1}$ involve a modulation of proinflammatory cytokine production. Pretreatment with 1 (50 and $100 \mathrm{mg} / \mathrm{kg}$, ip) or dexamethasone $(2 \mathrm{mg} / \mathrm{kg})$ inhibited the increase of IL- $1 \beta$ and TNF- $\alpha$ production induced by CFA (Figure 5a and b, respectively). Consistent with the present data, 1 was recently reported to show antiarthritic activity that was correlated with inhibition of IL-2, IFN- $\gamma$, and TNF- $\alpha$
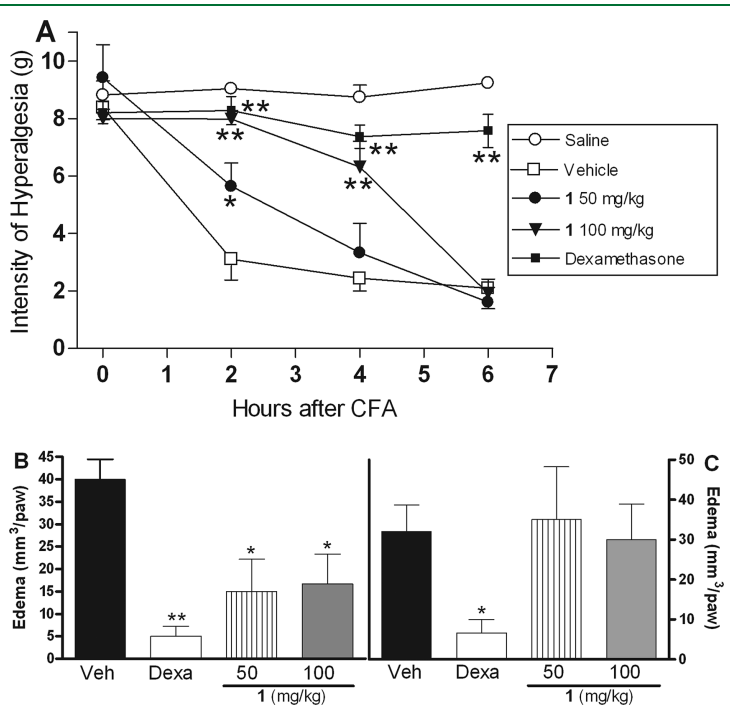

Figure 4. Effects of the bergenin (1) treatment on complete Freund's adjuvant (CFA)-induced paw inflammation. (a) Inflammatory hyperalgesia measured at 2, 4, and $6 \mathrm{~h}$ after the CFA intraplantar (ipl) stimulus. (b and c) Paw edema measured at 2 and $6 \mathrm{~h}$, respectively, after the CFA injection. Mice were injected with 1 (50 and $100 \mathrm{mg} / \mathrm{kg}$ ), vehicle $(2 \%$ DMSO in saline; control group), or dexamethasone ( $2 \mathrm{mg} / \mathrm{kg}$; positive control) by the ip route $40 \mathrm{~min}$ before CFA (injected at time zero). Data are expressed as means \pm SEM; $n=6$ mice per group. *Significantly different from the control group $(p<0.01)$; ${ }^{* *}$ significantly different from the control group $(p<0.001)$. Two-way ANOVA followed by the Bonferroni's test. production. ${ }^{9}$ Currently, it is well accepted that cytokines constitute a link between cellular injuries or immunological recognition and signs of inflammation. ${ }^{10-12}$ Different cell types, including macrophages, monocytes, and glial cells, produce IL- $1 \beta$ and TNF- $\alpha$, which in turn induce the production of other inflammatory mediators involved with cellular recruitment, fever, acute phase protein release, increase of vascular permeability, and hyperalgesia. ${ }^{23}$ Considering the important role of IL- $1 \beta$ and TNF- $\alpha$ during the inflammatory response, it may be suggested that the anti-inflammatory effect of $\mathbf{1}$ is related to an ability to inhibit the release of these cytokines.

The key role of $\mathrm{IL}-1 \beta$ and TNF- $\alpha$ on inflammatory hyperalgesia has been already demonstrated. It is known that a cascade of proinflammatory cytokines, including TNF- $\alpha$ and $\mathrm{IL}-1 \beta$, precedes the release of the final hyperalgesic mediators, i.e., prostaglandins and sympathetic amines. ${ }^{14,15}$ Cytokine antagonists are able to reduce inflammatory hyperalgesia in mice, indicating that cytokine activation is an important step in the development of inflammatory pain. ${ }^{24}$ IL- $1 \beta$ and TNF- $\alpha$ stimulate COX-2 expression and the production of prostaglandins, ${ }^{25-27}$ which are involved with nociceptive sensitization. ${ }^{28}$ Thus, the local injection of TNF- $\alpha$ and IL- $1 \beta$ produces hyperalgesia dependent on the release of prostanoids. ${ }^{12,29}$ Herein, it was described that $\mathbf{1}$ reduced $\mathrm{IL}-1 \beta$ and TNF- $\alpha$ levels. Since the sensitization of nociceptors is the common denominator of different types of pain, the reduction of IL- $1 \beta$ and TNF- $\alpha$ production can be responsible for the antinociceptive effect of $\mathbf{1}$ described herein. In addition, $\mathbf{1}$ inhibits COX-1 and COX-2 activity, ${ }^{30}$ reducing directly the prostanoid production. It was demonstrated that the intratecal administration of AINEs diminishes the first phase of the formalin test, suggesting an important contribution of the spinal COX activation during this phase. ${ }^{31}$ Therefore, it is possible that the $\mathbf{1}$ antinociceptive effect during the first phase of the formalin test is due to the COX enzyme inhibition. Woolf et al. ${ }^{32}$ showed that $\mathrm{COX}_{2}$, TNF- $\alpha$, and IL- $1 \beta$ mediate hyperalgesia induced by the ipl administration of CFA. Similarly, the role of TNF- $\alpha$ in overt pain models such as the formalin-evoked flinch behavior and acetic acid-evoked writhings has been demonstrated, since the pretreatment with antiserum against TNF- $\alpha$ partially reduces nociceptive behavior in these models. ${ }^{33,34}$

Pro- and anti-inflammatory cytokines are mediators for which the balance modulates the intensity of inflammatory hyperalgesia. ${ }^{14}$ Hyperalgesic cytokines induce inflammatory pain, ${ }^{15}$ while antiinflammatory cytokines inhibit the production of hyperalgesic cytokines and final mediators, reducing the inflammatory pain. ${ }^{16,17}$ IL-10 is an antihyperalgesic cytokine produced by inflammatory

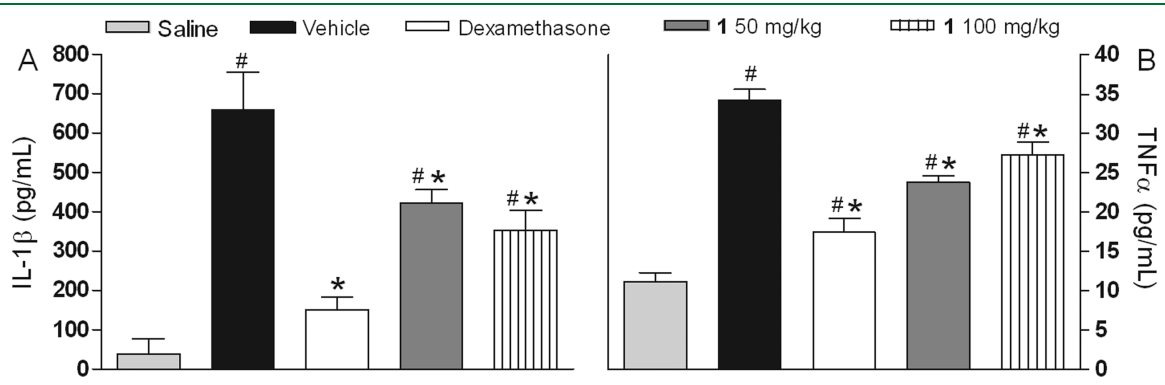

Figure 5. Effect of treatment with bergenin (1) on IL-1 $\beta$ (a) and TNF- $\alpha$ (b) paw levels. Mice were injected with 1 (50 and $100 \mathrm{mg} / \mathrm{kg})$, vehicle (2\% DMSO in saline; control group), or dexamethasone $(2 \mathrm{mg} / \mathrm{kg}$ ) by the ip route $40 \mathrm{~min}$ before the ipl injection of complete Freund's adjuvant (CFA). Saline group received an ipl injection of saline $(20 \mu \mathrm{L} / \mathrm{paw})$ instead of CFA. The paw levels of TNF- $\alpha$ and IL-1 $\beta$ were measured by ELISA $2 \mathrm{~h}$ after the CFA injection. Data are reported as means \pm SEM; $n=6$ mice per group. ${ }^{*}$ Significantly different from the saline group $(p<0.01)$; *significantly different from the control group $(p<0.01)$. One-way ANOVA followed by Tukey's test. 

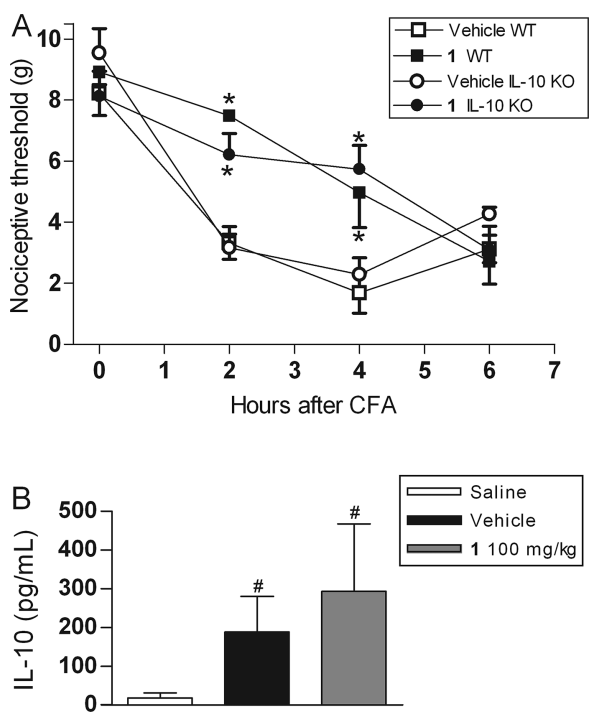

Figure 6. Effects of bergenin (1) on IL-10 paw levels and inflammatory hyperalgesia of IL-10-deficient mice. (a) Inflammatory hyperalgesia measured at 2, 4, and $6 \mathrm{~h}$ after the complete Freund's adjuvant (CFA) ipl injection. C57BL/6 IL-10-deficient mice (IL-10 KO) or C57BL/6 wild-type (WT) mice were injected with $1(100 \mathrm{mg} / \mathrm{kg})$ or vehicle (DMSO $2 \%$ in saline; control group) by the ip route $40 \mathrm{~min}$ before CFA (injected at time zero). (b) Paw levels of IL-10 measured by ELISA $3 \mathrm{~h}$ after CFA. C57BL/6 wild-type mice were injected with $1(100 \mathrm{mg} / \mathrm{kg})$ or vehicle by the ip route $40 \mathrm{~min}$ before CFA. The saline group received an ipl injection of saline $(20 \mu \mathrm{L} / \mathrm{paw})$ instead of CFA. Data are expressed as means \pm SEM; $n=6$ mice per group. ${ }^{*}$ Significantly different from the control group $(p<0.01)$; ${ }^{*}$ significantly different from the saline group $(p<0.05)$. Two-way ANOVA followed by Bonferroni's test.

cells. It has been shown that IL-10 inhibits pro-inflammatory cytokine production. ${ }^{35,36}$ Moreover, IL-10 inhibits the hyperalgesia induced by local administration of TNF- $\alpha$, IL- $1 \beta$, or IL- $6{ }^{17}$ Given the capacity of IL-10 to inhibit the production of TNF- $\alpha$ and $\mathrm{IL}-1 \beta$, in the present study we have investigated the possibility that IL-10 production contributes to the antinociception by 1 during inflammatory conditions. Disproving the contribution of IL-10 to antinociception induced by this compound, the administration of $\mathbf{1}(100 \mathrm{mg} / \mathrm{kg})$ produced a similar profile of antinociception in wild-type and IL-10-deficient mice (Figure 6a). Furthermore, the local production of IL-10 was not altered by such treatment (Figure 6b). Nazir et al. ${ }^{9}$ showed that $\mathbf{1}$ inhibits the production of proinflammatory Th1 cytokines (IL-2, IFN- $\gamma$, and TNF- $\alpha$ ) while potentiating anti-inflammatory Th2 cytokines (IL-4 and IL-5) in the peripheral blood of arthritic mice. IL-4 is produced primarily by $\mathrm{Th} 2$ lymphocytes and mast cells. It has been shown that local administration of IL-4 reduces inflammatory hyperalgesia, and this effect is associated with the inhibition of TNF- $\alpha$, IL- $1 \beta$, and IL-8 production. ${ }^{16}$ Considering the literature data, it is possible that the antinociceptive effects of 1 involve IL-4 induction, but this hypothesis needs to be confirmed.

The long-term administration of the available anti-inflammatory-analgesic drugs may lead to the development of multiple side effects such as gastrointestinal ulcers, bleeding, renal disorders, and immunosuppression. ${ }^{37-39}$ Taking this possibility into consideration, the systemic effects of $\mathbf{1}$ were studied. Treatment with $\mathbf{1}$ (50 and $100 \mathrm{mg} / \mathrm{kg}$, ip) in a single dose scheme over seven consecutive days did not affect the animal corporal mass and did not induce any variations in the general appearance or toxic signs in the animals when compared to vehicle-treated mice. Values obtained for urea and creatinine levels, used as parameters of renal function, did not differ from those of control mice (Table S1, Supporting Information). Moreover, the liver function, evaluated via hepatic enzymes (ALT and AST), and the number of blood circulating leukocytes were not altered by treatment with $\mathbf{1}$ in comparison to controls. Similarly, daily treatment with $\mathbf{1}$ was found safe from the viewpoint of gastric inflammatory events and ulcer induction at therapeutic dose levels. A microscopical evaluation of the stomach showed an intact mucosa with no inflammatory cell infiltrate, edema, erosion, or necrosis in mice treated daily with 1 (Table S2 and Figure S1, Supporting Information). Moreover, 1 was found to be safe up to $2 \mathrm{~g} / \mathrm{kg}$ per body weight in an acute toxicity test, with no sign of mortality or change in behavioral pattern. ${ }^{9}$ The low toxicity and the encouraging systemic effects reported here reinforce the potential of $\mathbf{1}$ for pharmacological development.

In contrast with nonsteroidal anti-inflammatory agents, inhibitors of cytokine production exhibit disease-modifying activities in animal models of chronic inflammation. ${ }^{40}$ Thus, the down-regulation of cytokines by nontoxic agents such as bergenin (1) may offer a therapeutic strategy for the control of some types of inflammatory disease. In line with this idea, anti-TNF- $\alpha$ therapies were shown effective in different diseases that are associated with pain, such as uveitis ${ }^{41}$ and rheumatoid arthritis. ${ }^{42,43}$ The results presented herein suggest that $\mathbf{1}$ possesses analgesic and anti-inflammatory activities owing to the inhibition of IL-1 $\beta$ and TNF- $\alpha$ release. A more in-depth evaluation of the mechanisms involved will need to be performed.

\section{EXPERIMENTAL SECTION}

General Experimental Procedures. NMR spectra were acquired on a Varian System 500 spectrometer, equipped with a XW4100 HP workstation. A high-resolution mass spectrum was recorded on a micrOTOF spectrometer (LC-IT-TOF, model 225-07 100-34, Bruker) with the positive ionization mode of the ESI source. Silica gel 60 (Merck) was used for column chromatography, and Si gel 60 PF254 (Merck) plates were used for purification of compounds by preparative TLC. All solvents used were of analytical grade (Merck).

Experiments were performed on male Swiss Webster C57BL/6 wildtype (WT) and IL-10-deficient (IL-10-KO) mice obtained from the Animal Facilities of Centro de Pesquisas Gonçalo Moniz. Animals (22-28 g) were housed in temperature-controlled rooms $\left(22-25{ }^{\circ} \mathrm{C}\right)$, under a 12:12 h light-dark cycle, with access to water and food ad libitum until use. All behavioral tests were perfomed between 8:00 A.M. and 5:00 P.M., and animals were used only once. Animal care and handling procedures were in accordance with International Association for the Study of Pain guidelines for the use of animals in pain research ${ }^{44}$ and the Institutional Animal Care and Use Committee FIOCRUZ L-IGM-012/09. Every effort was made to minimize the number of animals used and any discomfort. Behavioral tests were done without knowing to which experimental group each mouse belonged. Results shown are from two independent experiments performed.

Plant Material. The stem bark of Cenostigma gardnerianum Tul. (Leguminosae) was collected in the surroundings of Casa Nova, Bahia, Brazil, in August 2006, in authorized areas by IBAMA (Brazilian Institute for the Environment and Natural Resources) and received botanic identification by Dr. Luciano P. Queiroz. A voucher specimen has been deposited at the Herbarium of Universidade Estadual de Feira de Santana, Bahia, Brazil (HUEFS 78424). 
Extraction and Isolation. Bergenin (1,896 mg) was isolated from the stem bark $(1200 \mathrm{~g})$ of Cenostigma gardnerianum as a crystalline solid and was identified by spectroscopic data comparison according to literature procedures. ${ }^{45}$ The $\%$ purity of bergenin (1) used in the biological experiments carried out was determined by HPLC as $98 \%$.

Test Compounds and Stimuli. Indomethacin, dexamethasone, complete Freund's adjuvant, phosphate-buffered saline (PBS), Tween 20, phenylmethylsulfonyl fluoride (PMSF), benzamethonium chloride, EDTA, aproptinin A, Dulbecco's modified Eagle's medium (DMEM), and $3,3^{\prime}, 5,5^{\prime}$ - tetramethylbenzidine (TMB) were obtained from Sigma Chemical Company (St. Louis, MO, USA). Diazepam was obtained from Cristália (Itapira, São Paulo, Brazil). Gentamycin was obtained from Novafarma (Anápolis, Goiás, Brazil). Indomethacin was dissolved in 0.1 $\mathrm{M}$ Tris $\mathrm{HCl}$ pH 8.0 plus saline. Dexamethasone was dissolved in ethanol ( $10 \%$ in normal saline). Compound $\mathbf{1}$ was dissolved in $2 \%$ DMSO plus saline, and the remaining substances were dissolved directly in saline. Drugs were administrated by the intraperitoneal (ip) or intraplantar (ipl) routes, and the control group received the vehicle only.

Writhing Test. The ip antinociceptive doses of $\mathbf{1}$ were determined in mice using the writhing test. Acetic acid $(0.8 \% \mathrm{v} / \mathrm{v}, 10 \mathrm{~mL} / \mathrm{kg})$ was injected into the peritoneal cavities of mice, which were placed in a large glass cylinder, and the intensity of nociceptive behavior was quantified by counting the total number of writhes occurring between 0 and $30 \mathrm{~min}$ after a stimulus injection. ${ }^{18}$ The writhing response consists of a contraction of the abdominal muscle together with a stretching of the hind limbs. Antinociceptive activity was expressed as the writhing scores over $30 \mathrm{~min}$. Mice were treated with 1 , vehicle (2\% DMSO in saline; control group), or indomethacin (positive control) by the ip route $40 \mathrm{~min}$ before acetic acid.

Formalin Test. Mice were placed in an open Plexiglas observation chamber for $30 \mathrm{~min}$ to accommodate to their surroundings and then removed for formalin administration. Mice were gently restrained while the dorsum of the hind paw was administered subcutaneously (sc) with $20 \mu \mathrm{L}$ of $2.5 \%$ formalin (1:100 dilution of stock formalin solution, $37 \%$ formaldehyde in $0.9 \%$ saline), using a 30 gauge needle. Following injection, mice were returned to the observation chamber for a 60 min observation period. A mirror was placed behind the chamber to enable unhindered observation of the formalin-injected paw. Mice were observed from 0 to $10 \mathrm{~min}$ (early phase) and from 10 to $60 \mathrm{~min}$ (late phase), and a nociception score was determined for each period by counting the time that the animal spent licking the injected limb during the observation time. ${ }^{46}$ Mice were treated with 1 , vehicle (2\% DMSO in saline; control group), or indomethacin (positive control) by the ip route $40 \mathrm{~min}$ before formalin.

Inflammatory Pain Model. Mice were slightly anesthetized with halothane and received $20 \mu \mathrm{L}$ of complete Freund's adjuvant $(1 \mathrm{mg} / \mathrm{mL}$ of heat-killed Mycobacterium tuberculosis in $85 \%$ paraffin oil and $15 \%$ mannide monoleate) sc in the plantar region of the right hind paw, according to a method previously reported. ${ }^{47}$ Mechanical hyperalgesia and edema were measured by von Frey filaments and the paw edema test, as described below. Mice were injected with $\mathbf{1}$, vehicle (2\% DMSO in saline; control group), or dexamethasone (positive control) by the ip route $40 \mathrm{~min}$ before the ip injection of CFA. The saline group received an ip injection of saline $(20 \mu \mathrm{L} /$ paw $)$ instead of CFA.

Mechanical Hyperalgesia Evaluation. The threshold to mechanical stimulation was measured with von Frey filaments (Stoelting, Chicago, IL). In a quiet room, mice were placed in acrylic cages $(12 \times$ $10 \times 17 \mathrm{~cm}$ ) with wire grid floors $30 \mathrm{~min}$ before the beginning of the test. This consisted of evoking a hind paw flexion reflex with one of a series of filaments with logarithmically incremental stiffness $(0.0045-28.84 \mathrm{~g})$. A positive response was characterized by the removal of the paw followed by clear flinching movements. A tilted mirror placed under the grid provided a clear view of the hind paws of the mice. An up-down method was used to record the threshold. ${ }^{48}$
Paw Edema Test. The volume of each mouse paw was measured with a plesthismometer (Ugo Basile, Comerio, Italy) before (Vo) the ip injection of CFA and three $h$ after (VT), as described previously. ${ }^{49}$ The amount of paw swelling was determined for each mouse, and the difference between VT and Vo was taken as the edema value $\left(\mathrm{mm}^{3} / \mathrm{paw}\right)$.

Cytokine Measurements. Mice were injected with $\mathbf{1}$, vehicle (2\% DMSO in saline; control group), or dexamethasone (positive control) by the ip route $40 \mathrm{~min}$ before the ip injection of CFA. The saline group received an ip injection of saline $(20 \mu \mathrm{L} /$ paw $)$ instead of CFA. Skin tissues were removed from the paws two hours after the ipl injection of CFA in mice terminally anesthetized with halothane from each experimental group. Tissue proteins were extracted from $100 \mathrm{mg}$ tissue $/ \mathrm{mL}$ PBS to which $0.4 \mathrm{M} \mathrm{NaCl}, 0.05 \%$ Tween 20 , and protease inhibitors (0.1 mM PMSF, $0.1 \mathrm{mM}$ benzethonium chloride, $10 \mathrm{mM}$ EDTA, and $20 \mathrm{KI}$ aprotinin $\mathrm{A} / 100 \mathrm{~mL}$ ) were added. The samples were centrifuged for $10 \mathrm{~min}$ at $3000 \mathrm{~g}$, and the supernatant was frozen at $-70^{\circ} \mathrm{C}$ for later quantification. ${ }^{50}$ Interleukin $1 \beta$ (IL-1 $\beta$ ), tumor necrosis factor $\alpha$ (TNF$\alpha$ ), and interleukin 10 (IL-10) levels were estimated using commercially available immunoassay ELISA kits for mice (R\&D System, Minneapolis, MN, USA), according to the manufacturer's instructions. The results are expressed as picograms of cytokine per milliliter of protein solution. As controls, the concentrations of these cytokines were determined in naive and vehicle-treated mice.

Motor Function Assays. To evaluate possible nonspecific musclerelaxant or sedative effects of $\mathbf{1}$, mice were submitted to the Rotarod test. ${ }^{51}$ The Rotarod apparatus (Insight, Ribeirão Preto, Brazil) consisted of a bar with a diameter of $3 \mathrm{~cm}$, subdivided into five compartments. The bar rotated at a constant speed of $5 \mathrm{rpm}$ The animals were selected $24 \mathrm{~h}$ previously by eliminating those mice that did not remain on the bar for two consecutive periods of $120 \mathrm{~s}$. Animals were treated with diazepam (10 mg/kg, ip), 1 (100 mg/kg, ip), or vehicle, and $40 \mathrm{~min}$ afterward were placed on a rotating rod. The resistance to falling was measured up to $120 \mathrm{~s}$. The results are expressed as the average time (s) the animals remained on the Rotarod in each group. To assess the possible effects of 1 on locomotor activity, mice were evaluated in an open-field test. ${ }^{52}$ Mice were treated with diazepam (10 mg/kg, ip), 1 (100 mg/kg, ip), or vehicle, and $40 \mathrm{~min}$ afterward were placed individually in a wooden box $(40 \times 60 \times 50 \mathrm{~cm})$ with the floor divided into 12 squares. The number of squares crossed with the four paws was measured for a period of $3 \mathrm{~min}$.

Evaluation of the Systemic Effects of 1. Signs of toxicity, mortality, general behavior, and gastric injury, as well as leukogram and blood biochemical parameters (concentrations of creatinine, urea, alanine amino transferase/AST, and aspartate amino transferase/ALT) were evaluated after subchronic treatment with 1 . Animals were weighed and injected daily with a single dose of $\mathbf{1}$ (50 and $100 \mathrm{mg} / \mathrm{kg}$, ip) or the vehicle for seven consecutive days. At the end of the treatment, blood samples were collected from the retro-orbital plexus of the mice under light anesthesia. Biochemical analyses were performed on serum samples obtained after centrifugation of total blood without anticoagulants, at $2500 \mathrm{rpm}$ for $15 \mathrm{~min}$. Standardized diagnostic kits using a LABTEST spectrophotometer were employed in spectrophotometric determinations of the AST, ALT, urea, and creatinine concentrations. For the leukogram determination, an aliquot of blood per animal was placed in EDTA, and counts of leukocytes were carried out using a cell counter (Advia 60 Hematology System; Bayer, Tarrytown, NY, USA).

In order to evaluate possible gastric effects of the daily administration of 1, histopathological analysis of the stomachs was performed. After removal, the stomachs were opened through the greater curvature, washed with saline, fixed in $10 \%$ formalin solution, rinsed, dehydrated, and embedded in paraffin. Tissue blocks were sectioned at $3 \mu \mathrm{m}$ thickness (Cryostat CM 1800; Leica, Nussloch, Germany), stained with hematoxylin-eosin, and observed by light microscopy $(40 \times)$, in order to examine morphological alterations, inflammatory cell infiltration, edema, epithelial cell loss, and necrosis. The histopathological alterations were assessed using 
the following scores: 0 , absence; 1 , discrete; 2 , moderate; 3 , moderate to intense; 4, intense. ${ }^{53}$ For each stomach, 10 fields $(40 \times)$ were analyzed per section, and the results were expressed as means \pm SEM. Morphological analyses were performed by blinded observers.

Statistical Analysis. Data are presented as means \pm standard error of the means (SEM) of measurements made on 6-9 animals in each group. Comparisons between three or more treatments were made using one-way ANOVA with Tukey's posthoc test, or for repeated measures, two-way ANOVA with Bonferroni's posthoc test, as appropriate. All data were analyzed using Prism 4 computer software (GraphPad, San Diego, CA, USA). Statistical differences were considered to be significant at $p<0.05$.

\section{ASSOCIATED CONTENT}

S Supporting Information. Values obtained for urea, creatinine, hepatic enzymes (ALT and AST), and the number of blood circulating leukocytes after daily administration of $\mathbf{1}$ are presented in Table S1. Histopathological analysis of mouse stomachs after daily administration of $\mathbf{1}$ is presented in Figure S1 and Table S2. These materials are available free of charge via the Internet at http://pubs.acs.org.

\section{AUTHOR INFORMATION}

\section{Corresponding Author}

*Tel: +55-71-31762260. Fax: +55-71-31762272. E-mail: cfv@ ufba.br.

\section{ACKNOWLEDGMENT}

This work was supported by grants from Fundação de Amparo à Pesquisa do Estado da Bahia (FAPESB), Coordenação de Aperfeiçoamento de Pessoal de Nível Superior (CAPES), Rede Nordeste de Biotecnologia (RENORBIO), and Conselho Nacional de Pesquisa (CNPq).

\section{REFERENCES}

(1) Swarnalakshmi, T.; Sethuraman, M. G.; Sulochana, N.; Arivudainambi, R. Curr. Sci. 1984, 53, 917.

(2) Piegen, X. In Natural Products as Medicinal Agents; Beal, J. L.; Reinhard, E., Eds.; Hippokrates Verlag: Stuttgart, 1980; pp 100-117.

(3) Jahromi, M. A. F.; Chansouri, J. P. N.; Ray, A. B. Phytother. Res. 1992, 6, 180-183.

(4) Piacente, S.; Pizza, C.; de Tommasi, N. J. Nat. Prod. 1996, 59, $565-569$.

(5) Pu, H. L.; Huang, X.; Zhao, J. H.; Hing, A. Planta Med. 2002, $68,372-374$.

(6) Lim, H. K.; Kim, H. S.; Choi, H. S.; Oh, S.; Choi, J. J. Ethnopharmacol. 2000, 72, 469-474.

(7) Takahashi, H.; Kosaka, M.; Watanabe, Y.; Nakade, K.; Fukuyama, Y. Bioorg. Med. Chem. 2003, 11, 1781-1788.

(8) Goel, R. K; Maiti, R. N.; Manickam, M.; Ray, A. B. Indian J. Exp. Biol. 1997, 35, 1080-1083.

(9) Nazir, N.; Koul, S.; Qurishi, M. A.; Taneja, S. C; Ahmad, S. F.; Bani, S.; Qazi, G. N. J. Ethnopharmacol. 2007, 112, 401-405.

(10) Dinarello, C. A. Chest 2000, 118, 503-508.

(11) Faccioli, L. H.; Souza, G. E.; Cunha, F. Q.; Poole, S.; Ferreira, S. H. Agents Actions 1990, 30, 344-349.

(12) Ferreira, S. H.; Lorenzetti, B. B.; Bristow, A. F.; Poole, S. Nature 1988, 334, 698-700.

(13) Julius, D.; Basbaum, A. I. Nature 2001, 413, 203-210.

(14) Verri, W. A., Jr.; Cunha, T. M.; Parada, C. A.; Poole, S.; Cunha, F. Q.; Ferreira, S. H. Pharmacol. Ther. 2006, 112, 116-138.
(15) Cunha, T. M.; Verri, W. A., Jr.; Silva, J. S.; Poole, S.; Cunha, F. Q.; Ferreira, S. H. Proc. Natl. Acad. Sci. U. S. A. 2005, 102, 1755-1760.

(16) Cunha, F. Q.; Poole, S.; Lorenzetti, B. B.; Veiga, F. H.; Ferreira, S. H. Br. J. Pharmacol. 1999, 126, 45-50.

(17) Poole, S.; Cunha, F. Q.; Selkirk, S.; Lorenzetti, B. B.; Ferreira, S. H. Br. J. Pharmacol. 1995, 115, 684-688.

(18) Collier, H. O.; Dinneen, L. C.; Johnson, C. A.; Schneider, C. Br. J. Pharmacol. Chem. 1968, 32, 295-310.

(19) Hunskaar, S.; Hole, K. Pain 1987, 30, 103-114.

(20) Jachak, S. M.; Gautam, R.; Selvam, C.; Madhan, H.; Srivastava, A.; Khan, T. Fitoterapia 2011, 82, 173-177.

(21) Valério, D. A.; Georgetti, S. R.; Magro, D. A.; Casagrande, R.; Cunha, T. M.; Vicentini, F. T.; Vieira, S. M.; Fonseca, M. J.; Ferreira, S. H.; Cunha, F. Q.; Verri-Jr, W. A. J. Nat. Prod. 2009, 72, 1975-1979.

(22) Lima, F. O.; Nonato, F. R.; Couto, R. D.; Barbosa-Filho, J. M.; Nunes, X. P.; Ribeiro dos Santos, R.; Soares, M. B. P.; Villarreal, C. F. J. Nat. Prod. 2011, 74, 596-602.

(23) Dinarello, C. A. Int. Rev. Immunol. 1998, 16, 457-499.

(24) Cunha, J. M.; Sachs, D.; Canetti, C.; Poole, S.; Ferreira, S. H.; Cunha, F. Q. Br. J. Pharmacol. 2003, 139, 1135-1145.

(25) Crofford, L. J.; Wilder, R. L.; Ristimaki, A. P.; Sano, H.; Remmers, E. F.; Epps, H. R.; Hla, T. J. Clin. Invest. 1994, 93, 1095-1101.

(26) Schafers, M.; Sorkin, L. S.; Sommer, C. Pain 2003, 104, 579-588.

(27) Zucali, J. R.; Dinarello, C. A.; Oblon, D. J.; Gross, M. A.; Anderson, L.; Weiner, R. S. J. Clin. Invest. 1986, 77, 1857-1863.

(28) Ferreira, S. H.; Nakamura, M. Prostaglandins 1979, 18, 179-190.

(29) Cunha, F. Q.; Poole, S.; Lorenzetti, B. B.; Ferreira, S. H. Br. J. Pharmacol. 1992, 107, 660-664.

(30) Jachak, S. M.; Gautam, R.; Selvam, C.; Madhan, H.; Srivastava, A.; Khan, T. Fitoterapia 2011, 82, 173-177.

(31) Yamamoto, T.; Nozaki-Taguchi, N. Anesth. Analg. 2002, 94, 962-967.

(32) Woolf, C. J.; Allchorne, A.; Safieh-Garabedian, B.; Poole, S. Br.J. Pharmacol. 1997, 121, 417-424.

(33) Granados-Soto, V.; Alonso-Lopez, R.; Asomoza-Espinosa, R.; Rufino, M. O.; Gomes-Lopes, L. D.; Ferreira, S. H. Proc. West. Pharmacol. Soc. 2001, 44, 15-17.

(34) Ribeiro, R. A.; Vale, M. L.; Ferreira, S. H.; Cunha, F. Q. Eur. J. Pharmacol. 2000, 391, 97-103.

(35) Fiorentino, D. F.; Zlotnik, A.; Mosmann, T. R.; Howard, M.; O'Garra, A. J. Immunol. 1991, 147, 3815-3822.

(36) Kasama, T.; Strieter, R. M.; Lukacs, N. W.; Lincoln, P. M.; Burdick, M. D.; Kunkel, S. L. J. Clin. Invest. 1995, 95, 2868-2876.

(37) Peskar, B. M. Biochim. Biophys. Acta 1977, 487, 307-314.

(38) Schäcke, H.; Döcke, W. D.; Asadullah, K. Pharmacol. Ther. 2002, 96, 23-43.

(39) Tapiero, H.; Ba, G. N.; Couvreur, P.; Tew, K. D. Biomed. Pharmacother. 2002, 56, 215-222.

(40) Geiger, T.; Rordorf, C.; Cosenti-Vargas, A.; Ferrini, P. G.; Widler, L.; Glatt, M.; Vosbeck, K. J. Rheumatol. 1994, 21, 1992-1997.

(41) Smith, J. A.; Thompson, D. J.; Whitcup, S. M.; Suhler, E.; Clarke, G.; Smith, S.; Robinson, M.; Kim, J.; Barron, K. S. Arthritis Rheumatol. 2005, 53, 18-23.

(42) Haraoui, B. J. Rheumatol. Suppl. 2005, 72, 46-47.

(43) Moreland, L. W. Drugs Today (Barc.) 1999, 35, 309-319.

(44) Zimmermann, M. Pain 1983, 16, 109-110.

(45) Frick, W.; Hofmann, J.; Fischer, H.; Schmidt, R. R. Carbohydr. Res. 1991, 210, 71-77.

(46) Dubuisson, D.; Dennis, S. G. Pain 1977, 4, 161-174.

(47) Kassuya, C. A.; Silvestre, A. A.; Rehder, V. L.; Calixto, J. B. Eur. J. Pharmacol. 2003, 478, 145-153.

(48) Chaplan, S. R.; Bach, F. W.; Pogrel, J. W.; Chung, J. M.; Yaksh, T. L. J. Neurosci. Methods 1994, 53, 55-63.

(49) Winter, C. A.; Risley, E. A.; Nuss, G. W. Proc. Soc. Exp. Biol. Med. 1962, 111, 544-547.

(50) Santiago, H. C.; Braga Pires, M. F.; Souza, D. G.; Roffê, E.; Côrtes, D. F.; Tafuri, W. L.; Teixeira, M. M.; Vieira, L. Q. Microbes Infect. 2006, 8, 2569-2577. 
(51) Vaz, Z. R.; Filho, V. C.; Yunes, R. A.; Calixto, J. B. J. Pharmacol. Exp. Ther. 1996, 278, 304-312.

(52) Rodrigues, A. L.; da Silva, G. L.; Matteussi, A. S.; Fernandes, E. S.; Miguel, O. G.; Yunes, R. A.; Calixto, J. B.; Santos, A. R. Life Sci. 2002, 70, 1347-1358.

(53) Laine, L.; Weinstein, W. M. Gastroenterology 1988, 94, 12541262. 